\title{
Research on Fiberglass Grid Preventing Cracks Used as Interlayer between Old Cement Concrete Pavement and Asphalt Overlay
}

\author{
Yuqing Yuan ${ }^{1, a}$, Xuechan $\mathrm{Li}^{2, \mathrm{~b}}$, Wei $\mathrm{Li}^{1, \mathrm{c}}$, Tao Guo ${ }^{1, \mathrm{~d}}$ \\ ${ }^{1}$ School of Civil Engineering and Architecture, Henan University, Kaifeng 475004, Henan, China \\ ${ }^{2}$ College of Philosophy and Public Administration, Henan University, Kaifeng 475004, Henan, \\ China \\ ayuanyq@126.com, byroad@126.com, ${ }^{\mathrm{c}} 250315995 @ q q . c o m,{ }^{d}$ zhulin356@yahoo.com.cn
}

Keywords: road engineering, glass fiber grid, direct shear test, asphalt overlay, anti-crack

\begin{abstract}
To solve the problems of grid preventing crack, which is used as interlayer between old cement concrete pavement and asphalt overlay, the authors carried through finite element calculations, theoretical analyses, and laboratory tests simulating the field situations. Mechanical analysis proved that grid can obviously reduce the maximum principal stress, equivalent stress, and maximum shear stress at the bottom points of the asphalt overlay. Direct shear layer tests found that the damages occur on the surface of old cement concrete near to grid, the greater the loading rate the easier is it to destroy, and it will obtain best anti-cracking results after roughed treatments. The results showed that glass fiber grid can prevent the reflection cracks from the old cement and asphalt overlay, and can improve the interlayer work, and the roughed treatment on old cement road surface is an important guarantee to achieve this objective.
\end{abstract}

\section{Introduction}

Glass fiber grid is a new kind of geosynthetic, with advantages of high tensile modulus and intension, high temperature resistance and corrosion resisting. In 1980's the material was firstly used by the British in asphalt pavement reinforcement and preventing crack, which obtained a better effect. With the rapid development of the old pavement modification in a wide range, the fiberglass grid is gradually used in interlayer between asphalt and old cement concrete pavement. The research shows that the special material can delay reflecting crack of asphalt overlaying structure both at home and abroad[1-3]. However, engineering application effects are not very ideal and mechanism of against the crack is in the primary stage. This paper will explore in-depth study through the theory and experiment analysis method, so as to provide scientific guidance for engineering application.

\section{Mechanism of anti-cracking}

Mechanical analysis. Finite element model is built to calculate stress coupled temperature and load[4,5], shown in Fig.1. From the changing trend, the maximum principal stress, equivalent stress and maximum shear stress (3 stresses) sharply reduce when the tensile modulus of fiberglass grid increases from $0 \mathrm{MPa}$ to $1000 \mathrm{MPa}$. When the tensile modulus meets $500 \mathrm{MPa}$, the 3 stresses drop by $23 \%, 26.7 \%$ and $26.6 \%$, respectively, than that without interlayer. When the tensile modulus reaches $1000 \mathrm{MPa}$, the 3 stresses drop by 40\%, 31.9\% and 38.2\%, respectively, than that without interlayer. When the tensile modulus ranges from $1000 \mathrm{MPa}$ to $5000 \mathrm{MPa}$, the stress curve is gradually flattened. Therefore, $1000 \mathrm{MPa}$ is the best to select fiberglass grid modulus. 


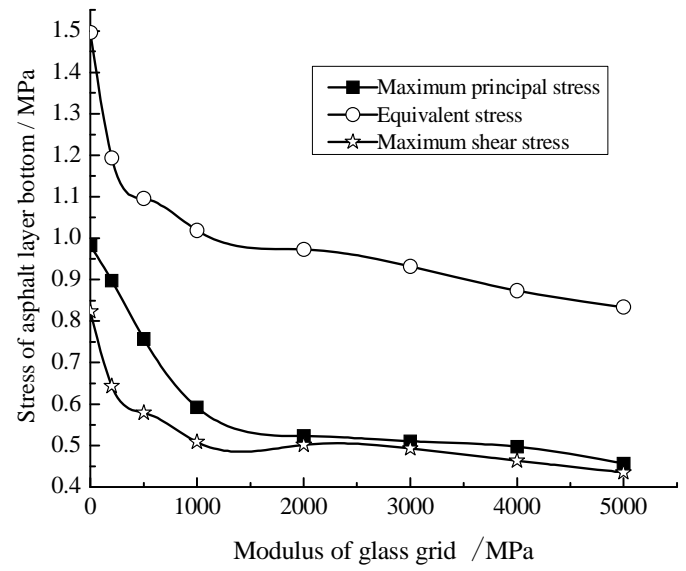

Fig.1 Reduction functions of fiberglass grid on asphalt layer bottom stress

Theory analysis. The American asphalt institute deems that the reflecting crack of asphalt overlaying old cement pavement is from deflection for the velocity of vehicle load far higher than temperature changing the cement pavement streth. Therefore, the key technology to preventing crack is to lower deflection of existed cracks and to increase the overlay flexural strength and shear strength.

As high modulus, up to $67 \mathrm{GPa}$, fiberglass grid can be used in asphalt overlay to restrain strain and release stress. Meanwhile, as reinforcement materials, fiberglass grid can improve tensile and shear capacity of overlaying structure, which achieves the purpose of reducing crack[6].

\section{Direct shear test}

Experimental preparation. First, cement samples are made to simulate the old cement concrete pavement. According to the cement concrete strength standard C25, the prepared mixtures are put into Marshall test mode. After vibration moulding, the surface is floated. Then, the sample is demoulded after 24 hours. After that, the test sample will be kept in standard curing room for 28 days. The concrete surface condition is divided into 3 levels: smooth, the original and rough. With cutting machine, each specimen was cut into two from the middle. Artificial plane is as the original surface with. After polishing, the cutting face is as smooth surface. And a rough surface is from the artificial cutting groove on the plane.

As sticky layer oil, hot asphalt was well distributed, with $0.4 \mathrm{~L} / \mathrm{m} 2$. Then, grid was sticked on the test specimen surface, appropriately planished with a hot shovel, which is conducted as a interlayer cracking -resistant material. Then, hot modified AC-16 was poured into the hot testing mold. Immediately pressure head of press machine was put after tamping. Adjusting the compression rate, pressure is met $50 \mathrm{kN}$, and is kept for 3 minutes. Until specimen cooling to a specified temperature does demould for standby.

Experimental design. According to engineering practice, four test schemes were drafted, shown in Table 1, which is considered about three surfaces of cement concrete samples and two shearing rates.

Table 1 Test scheme summarizing

\begin{tabular}{|c|c|c|c|c|}
\hline $\begin{array}{c}\text { Scheme } \\
\text { number }\end{array}$ & $\begin{array}{c}\text { Surface condition of } \\
\text { cement concrete } \\
\text { samples }\end{array}$ & $\begin{array}{c}\text { Skid resistance } \\
\text { coefficient }(B P N)\end{array}$ & $\begin{array}{c}\text { Test } \\
\text { temperature/ }{ }^{\circ} \mathrm{C}\end{array}$ & $\begin{array}{c}\text { Shear } \\
\text { rate/(mm/min) }\end{array}$ \\
\hline I & Original & 53 & 15 & 10 \\
\hline II & Original & 53 & 15 & 50 \\
\hline III & Cutting & 60 & 15 & 10 \\
\hline IV & Smooth & 44 & 10 \\
\hline
\end{tabular}

Data analysis. The tests were put forward with JHY-A structure and material shearing instrument, shown in Fig. 2-5. 


\section{Contrast of I scheme with II scheme}

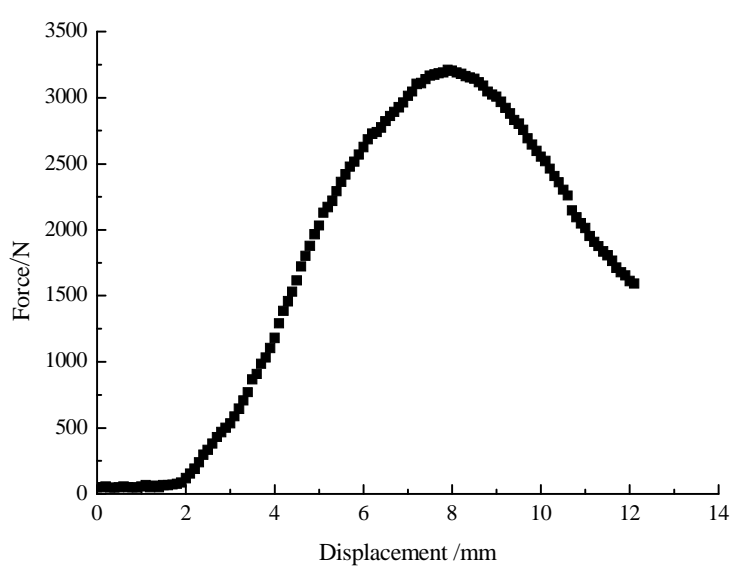

Fig. 2 Direct shear curve of scheme I

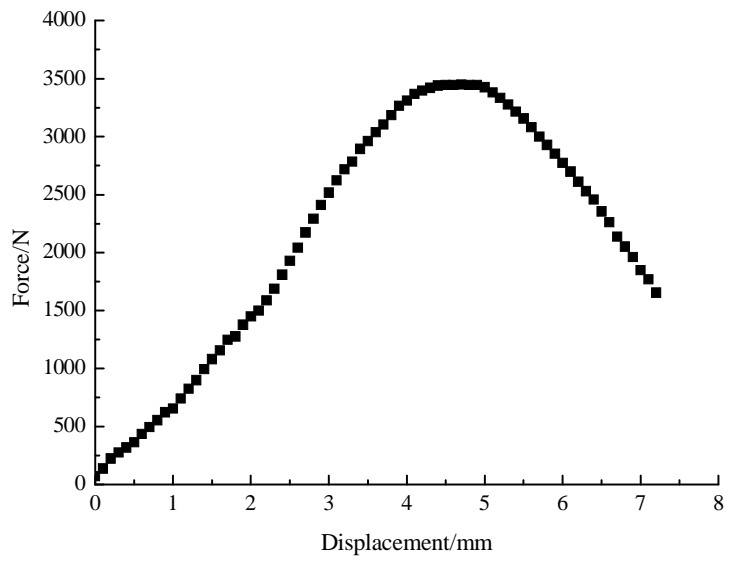

Fig. 3 Direct shear curve of scheme II

As for direct shearing curve of scheme I, shown in Fig. 2, displacement is $8 \mathrm{~mm}$ when it achieves the most strong value about $3500 \mathrm{~N}$. Then, grid is separated from cement concrete surface when the displacement meets $12 \mathrm{~mm}$. So far as to direct shearing curve of scheme II, shown in Fig. 3, displacement is $5 \mathrm{~mm}$ when it achieves the most strong value about $3500 \mathrm{~N}$. Then, grid is separated from cement concrete surface when the displacement meets $7.5 \mathrm{~mm}$. It is known that loading rate of scheme II and scheme I is $50 \mathrm{~mm} / \mathrm{min}, 10 \mathrm{~mm} / \mathrm{min}$, respectively. In the two situations, the maximum shear stress are all $3500 \mathrm{~N}$, yet the displacement of scheme II is $3 \mathrm{~mm}$ less than that scheme I. With increasing of shear stress, the separation occurs between grid and cement concrete, resulting into ruin. Destruction interlayer displacement of scheme II is less $4.5 \mathrm{~mm}$ than that of scheme I. The tests show that loading rate affected layer shearing. The greater the loading rate is, the smaller destroyed deformation is, more likely to damage.

\section{Contrast of III scheme with I scheme}

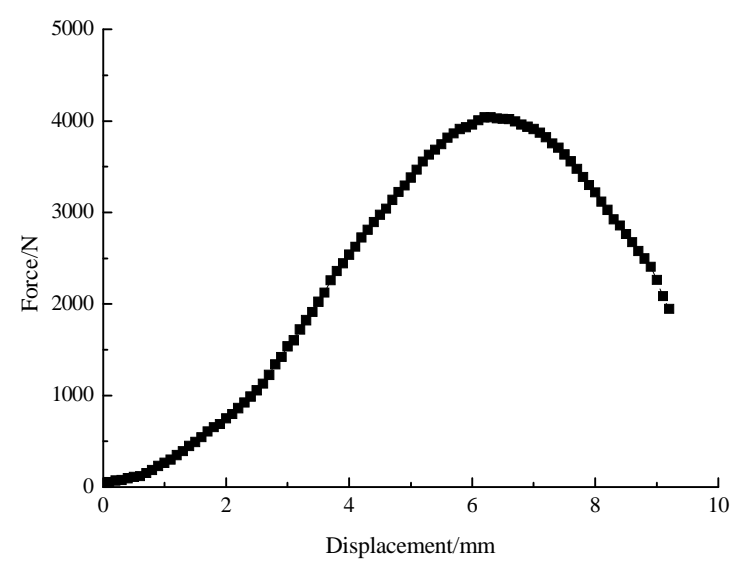

Fig. 4 Direct shear curve of scheme III

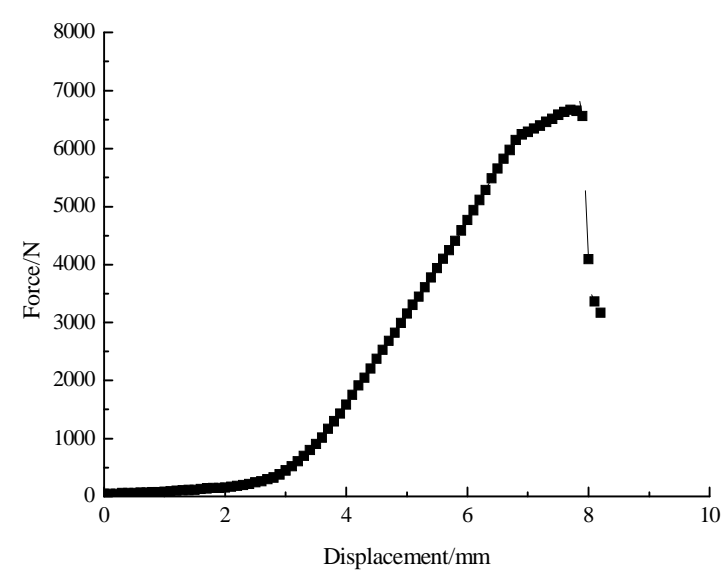

Fig. 5 Direct shear curve of scheme IV

Fig. 4 shows the direct shear curve displacement is $6.5 \mathrm{~mm}$ when meets the maximum stress $4500 \mathrm{~N}$. When the displacement reach $9 \mathrm{~mm}$, the test specimen destroy for grid separation from the cement concrete surface. Compared with scheme III, except surface state, the loading rate and test temperature are the same. The maximum shear stress of scheme III reaches $4000 \mathrm{~N}$, which is more $500 \mathrm{~N}$ than scheme I. It is indicated that cement concrete surface affects the interlayer shearing action, which says that the cutting surface has a good ability than the original one.

\section{Contrast of IV scheme with III scheme}

As for direct shear curve of scheme IV, the displacement is $8 \mathrm{~mm}$ when maximum load reach $7500 N$. Then, it rapidly destroy for the grid separation from cement concrete surface. Compared 
with scheme IV and scheme III, the loading rate and temperature are the same. The latter is with cutting surface, and the former has a smooth surface. The maximum shear stress of scheme IV is $3000 \mathrm{~N}$ more than the scheme III. Compared with scheme IV and scheme I, the loading rate and temperature are the same. The maximum shear stress of scheme IV is $4000 \mathrm{~N}$ more than the scheme I. Therefore, only shear ability speaking, a smooth surface is the strongest, then rough treatment, the worst is original surface. However, learn from Fig.5, smooth surface produces suddenly destruction when achieves maximum shear value, with a small interlayer displacement and deformation.

\section{Conclusions}

The finite element calculation shows that the maximum principal stress, equivalent stress and maximum shear stress of asphalt overlay bottom have obviously cut down with the tensile modulus of fiberglass grid. When the modulus reaches $1000 \mathrm{MPa}$, the effect is the best. The indoor test indicates the interlayer destruction occurs the surface between fiberglass grid and cement concrete specimen. The loading rate affects interlayer shear greatly. The more is the loading rate, the smaller deformation is. In other word, the greater is the speed, the more likely occurs damaged. The surface condition effect on interlayer shear stress. The cutting surface has more shear ability than original surface. And the surface roughness handling is the most scientific method to ideal resisting shear.

\section{Acknowledgement}

The work described in this paper was supported by the National western traffic scientific \& technological program of China (No.200531881213), science \& technology project of Henan transport department (No.2010PII10), and Education Department of Henan Province Natural Science Research Project (No.2011A580001). The authors would like to thank Prof. X.C. Wang for his valuable and helpful comments.

\section{References}

[1] R.Kirschner: Airport Forum,Vol. 20 (1990), p. 8-10.

[2] G.H. Fu, Y.J. Lu: China civil engineering journal, Vol. 35 (2002), p. 57-61.

[3] C.H. Wang, X.C. Wang: China Journal of Highway and Transport, Vol. 21 (2008), p. 29-34.

[4] B.Y. Chen, T. Jiang,Q.Y. Meng: Journal of Wuhan University of Technology, Vol. 29 (2007), p. 170-172.

[5] H.Z.Yu, D. Huang,W. Tang: Journal of Wuhan University of Technology, Vol. 30 (2008), p. 57-61.

[6] Y.F. Guo, J.X. Cui, C.G. Zhang: Journal of Wuhan University of Technology, Vol. 29 (2007), p.160-162. 